OCCASIONAL PAPER

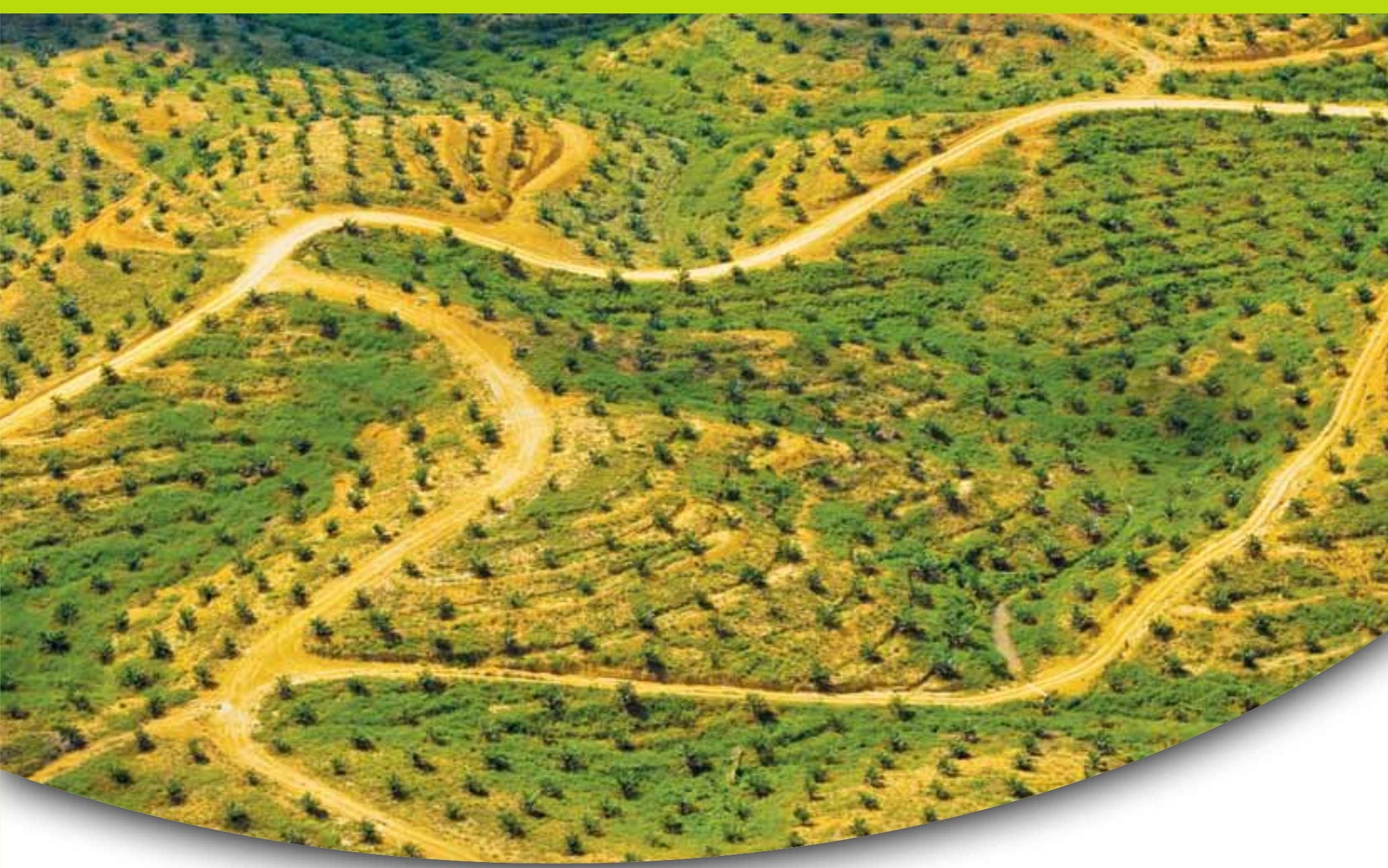

\title{
A review of environmental issues in the context of biofuel sustainability frameworks
}

Manuel R. Guariguata

Omar R. Masera

Francis X. Johnson

Graham von Maltitz

Neil Bird

Patricia Tella

René Martínez-Bravo

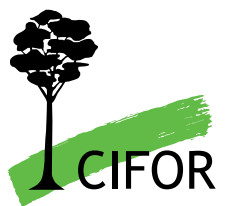





\title{
A review of environmental issues in the context of biofuel sustainability frameworks
}

\author{
Manuel R. Guariguata \\ CIFOR \\ Omar R. Masera \\ Universidad Nacional Autónoma de México \\ Francis $X$. Johnson \\ Stockholm Environment Institute \\ Graham von Maltitz \\ Council on Scientific and Industrial Research \\ Neil Bird \\ Joanneum Research \\ Patricia Tella \\ Stockholm Environment Institute \\ René Martínez-Bravo \\ Universidad Nacional Autónoma de México
}


Occasional Paper 69

(C) 2011 Center for International Forestry Research All rights reserved

$978-602-8693-62-2$

Guariguata, M.R., Masera, O.R., Johnson, F.X., von Maltitz, G., Bird, N., Tella, P. and Martínez-Bravo, R. 2011 A review of environmental issues in the context of biofuel sustainability frameworks. Occasional Paper 69. CIFOR, Bogor, Indonesia.

Cover photo @ World Wide Fund for Nature Deutschland (www.wwf.de/living-planet-report)

This report has been produced with financial assistance from the European Union, under the project 'Bioenergy, sustainability and trade-offs: Can we avoid deforestation while promoting bioenergy?' The objective of the project is to contribute to sustainable bioenergy development that benefits local people in developing countries, minimises negative impacts on local environments and rural livelihoods, and contributes to global climate change mitigation. The project will achieve this by producing and communicating policy-relevant analyses that can inform government, corporate and civil society decision making related to bioenergy development and its effects on forests and livelihoods. The project is managed by the Center for International Forestry Research (CIFOR) and implemented in collaboration with the Council on Scientific and Industrial Research (South Africa), Joanneum Research (Austria), the Universidad Nacional Autónoma de México and the Stockholm Environment Institute. The views expressed herein can in no way be taken to reflect the official opinion of the European Union.

\section{CIFOR}

Jl. CIFOR, Situ Gede

Bogor Barat 16115

Indonesia

$\mathrm{T}+62(251) 8622-622$

$\mathrm{F}+62(251) 8622-100$

E cifor@cgiar.org

www.cifor.org

Any views expressed in this publication are those of the authors. They do not necessarily represent the views of CIFOR, the authors' institutions or the financial sponsors of this publication. 


\section{Table of contents}

$\begin{array}{lll}\text { Abbreviations } & \mathbf{v}\end{array}$

Executive summary vi

1 Introduction 1

2 Overview of biofuel sustainability frameworks 3

2.1 European Union Renewable Energy Directive 5

$\begin{array}{ll}2.2 & \text { Roundtable on Sustainable Biofuels } \\ & 6\end{array}$

2.3 Roundtable on Sustainable Palm Oil 6

2.4 Round Table on Responsible Soy Association $\quad 7$

$\begin{array}{ll}2.5 & \text { Better Sugarcane Initiative }\end{array}$

$\begin{array}{ll}2.6 & \text { Forest Stewardship Council }\end{array}$

3 Environmental issues in sustainability frameworks 9

3.1 Biodiversity, soil, water and environmental impacts 9

$\begin{array}{ll}\text { 3.2 Land use change (direct and indirect) and associated greenhouse gas emissions } & 10\end{array}$

$\begin{array}{ll}3.3 & \text { Main limitations of the frameworks } \\ & 12\end{array}$

$4 \quad$ Improving biofuel sustainability frameworks: Key issues and challenges $\quad 17$

$\begin{array}{ll}4.1 & \text { Integration and harmonisation } \\ & 17\end{array}$

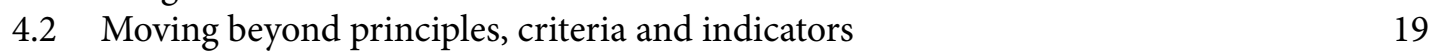

$\begin{array}{ll}4.3 & \text { Limitations of principles, criteria and indicators } \\ \end{array}$

5 Conclusions 23

6 References $\quad 25$ 


\section{List of tables and boxes}

\section{Tables}

1 A broad typology of biofuel sustainability frameworks and certification schemes by governance level and adoption requirements

2 Environmental issues in the six biofuel sustainability frameworks

3 Compatibility of criteria on land use change and greenhouse gas emissions in sustainability frameworks (assessed against EU RED)

Box

1 Proposals for a uniform (minimum) set of biofuel standards 


\section{Abbreviations}

$\begin{array}{ll}\text { BSI } & \text { Better Sugarcane Initiative } \\ \text { EC } & \text { European Commission } \\ \text { EU RED } & \text { European Union Renewable Energy Directive } \\ \text { FSC } & \text { Forest Stewardship Council } \\ \text { GATT } & \text { General Agreement on Tariffs and Trade } \\ \text { GHG } & \text { Greenhouse gas } \\ \text { HCV } & \text { High conservation value } \\ \text { IPCC } & \text { Intergovernmental Panel on Climate Change } \\ \text { ISO } & \text { International Organization for Standardization } \\ \text { LUC } & \text { Land use change } \\ \text { NGO } & \text { Nongovernmental organisation } \\ \text { PCI } & \text { Principles, criteria and indicators } \\ \text { RSB } & \text { Roundtable on Sustainable Biofuels } \\ \text { RSPO } & \text { Roundtable on Sustainable Palm Oil } \\ \text { RTRS } & \text { Round Table on Responsible Soy Association } \\ \text { WTO } & \text { World Trade Organization }\end{array}$




\section{Executive summary}

With the rapid growth of biofuel production and consumption, and the proliferation of policy decisions supporting this expansion, concerns about the biofuel sector's environmental and social impacts are increasing. Consequently, a range of actors among them governments, multilateral institutions, nongovernmental organisations and multistakeholder industry groups - have created sustainability frameworks, some mandatory, others voluntary. This report examines how the most developed sustainability frameworks for feedstock production (including biofuels) address key environmental issues. It identifies critical gaps in these frameworks and proposes areas for improvement. The frameworks analysed are the European Union Renewable Energy Directive (EU RED), Roundtable on Sustainable Biofuels (RSB), Roundtable on Sustainable Palm Oil (RSPO), Round Table on Responsible Soy Association (RTRS), Better Sugarcane Initiative (BSI) and the Forest Stewardship Council (FSC).

The key findings of the report are as follows:

- The frameworks share broad sustainability principles. However, they differ greatly in terms of their comprehensiveness and how they apply specific indicators for environmental issues, particularly with respect to land use change (both direct and indirect), allocation of degraded land for feedstock cultivation, and related accounting of greenhouse gas emissions.

- There are unresolved conflicts regarding the best options for implementing sustainability concerns: through gradual, improvement-based certification systems (e.g. International Organization for Standardization [ISO]) vs. criteria and indicator approaches; harmonised global sustainability frameworks vs. specific frameworks; and mandatory vs. market-based schemes.

- Such conflicts and possible trade impacts arise in part because of the lack of documented practical experience, as biofuel sustainability frameworks have been implemented only recently. Further efforts may be required to systematically document progress in their implementation. Designing tiered approaches to compliance may provide room for middle ground so that some aspects can be tackled through adherence to strict standards (related for example to habitat conversion) while other aspects can be systematically improved over time.

- It is not yet clear which of the frameworks would best ensure minimal impacts from land use change, including allocation of degraded land for feedstock cultivation and guidance on best management practices. Similarly, no clear consensus exists on which criteria and indicators should be included in all circumstances or which sustainability framework should become the global or international standard. Any global standard may, however, be less effective and/or less desirable compared to regional standards.

- Avoiding indirect land use change will be almost impossible to control solely through projectlevel certification of good practice. Enhancing productivity in the agricultural sector could help to reduce indirect land use change, especially in regions where production levels are currently low by international standards. The application of integrated approaches to land use planning that consider biodiversity issues as well as agricultural practices with biodiversity considerations may also be necessary. National policies should also be developed to encourage effective land use planning and application of agricultural best practice.

In the absence of sufficient hard data with which to gauge the effectiveness of existing sustainability frameworks, the report notes that the standards of these frameworks are not sufficient to mitigate the effects of direct and indirect land use change and promote environmental conservation. A key recommendation, therefore, is that such standards should be complemented by other policy instruments. Furthermore, as sustainability frameworks are only a means to an end, they must be supported by practical guidance, effective interpretation of standards, principles and criteria, and development of verifiable indicators, along with the provision of appropriate tools, approaches and capacity building activities. 


\section{Introduction}

$\mathrm{W}$ ith the rapid growth of biofuel production and consumption, and the proliferation of policy decisions supporting this expansion, especially in Brazil, the EU and USA, concerns about the long-term sustainability of biofuel development are increasing. In particular, the USA and EU have set targets for renewable energy to constitute $20 \%$ and $10 \%$, respectively, of all transport fuel by 2020 - targets that will require large amounts of biofuel. This raises questions about the feasibility of biofuel production and its associated environmental, social and economic impacts.

Some authors argue that the global demand for agro-industrial expansion, including biofuel feedstocks, is likely to be met partly at the expense of intact and/or undisturbed forest - mostly across the tropics, rather than permanent cropland areas (Gibbs et al. 2010). Another topic of debate is whether there is sufficient 'degraded' or otherwise available land to support such expansion (Schoneveld 2010).

Although analysing the sustainability of biofuel production began as an academic exercise, it is becoming a mandatory requirement for producers that seek to enter international markets such as the EU. The issue is also affecting imports in some consumer countries. In recent years, several initiatives, some mandatory, others voluntary, have been introduced and frameworks developed, by various governments, multilateral institutions, nongovernmental organisations (NGOs) and certification bodies. Among these are regulatory frameworks created by the $\mathrm{EU}$,
Germany, the Netherlands, the UK and the USA. Other relevant initiatives are those concerning the voluntary adoption of sustainable production standards linked to the implementation of certification schemes.

'Sustainability' as it applies to biofuel production, transport and consumption has not been unanimously defined. However, a common, core concept is that 'sustainable' production can ensure the continued productive capacity of the natural resources on which it is based, is economically feasible and is socially and environmentally acceptable. In this regard, standards and certification schemes that cover the entire lifecycle of biofuels (e.g. production, processing and transport) are considered viable strategies to ensure the sector adheres to principles of sustainable development. In particular, several standards addressing sustainable production of bioenergy or biofuel feedstocks include principles and criteria designed to preserve biological diversity and ecosystem integrity, to reduce greenhouse gas (GHG) emissions and mitigate the effects of land use change (LUC), as uncontrolled expansion of bioenergy feedstocks may diminish the provision of ecosystem services.

The extent to which biofuel sustainability frameworks address these issues and incorporate validated performance indicators is the focus of this report. Not all the sustainability frameworks examined here relate directly to biofuel production (as most feedstocks have other uses for food and fibre), but they have direct implications for the debate on biofuel sustainability. The term 'biofuel 
sustainability framework' should therefore be interpreted in this light. Furthermore, sustainability frameworks are at different stages of development and implementation, and many of them are incipient. Consequently, there is little guidance on how to assess the effectiveness of sustainability frameworks, particularly from an environmental perspective. The report also identifies critical gaps in the frameworks analysed and proposes areas for improvement, with a focus on the implications of applying biofuel standards that reduce the risk of deforestation.

The frameworks under review were selected according to their overall relevance in the context of large-scale cultivation of feedstocks across the world (sugarcane, oil palm, soybeans, woody biomass) and their global importance in influencing production, consumption and trade between producing and importing countries and/or regions. The frameworks analysed in this report are:

- European Union Renewable Energy Directive (EU RED)

- Roundtable on Sustainable Biofuels (RSB)

- Roundtable on Sustainable Palm Oil (RSPO)
- Round Table on Responsible Soy Association (RTRS)

- Better Sugarcane Initiative (BSI)

- Forest Stewardship Council (FSC)

With the exception of the EU RED, these frameworks are voluntary certification schemes in which certified operators agree to a set of principles and guidelines. For large-volume commodities such as palm oil, soybean and sugarcane - all of which are used as biofuel feedstock and are considered in this report - 'roundtables' involving a range of stakeholders along the production chain (government, NGOs, industry, importers, exporters) have been established. The FSC is somewhat different in that it certifies the performance of a forestry operation and is not concerned with feedstocks for biofuels per se; however, the expected commercial use of woody feedstocks for second generation biofuels implies its future relevance. The following section sets out the background and context of the six sustainability frameworks analysed in this report and then provides a detailed description of each framework. 


\section{Overview of biofuel sustainability frameworks}

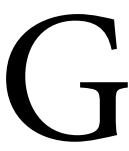
overnments across the world have issued laws, regulations and decrees related to biofuel production and consumption, many of which contain concepts and provisions addressing sustainability. However, some laws do little more than simply mention generic sustainability principles or considerations, whereas others incorporate a systematic and continuous effort to improve sustainability frameworks. There are also differences in the way biofuel sustainability frameworks are implemented and enforced, whether through national legislation in the producing country, through voluntary adoption or through a combination of both (Table 1). Such differences and particular combinations of approaches may determine specific outcomes from a governance standpoint (Cashore et al. 2010). This report analyses two broad approaches in the context of sustainability frameworks, across the twodimensional continuum depicted in Table 1.

The first approach, involving mandatory implementation, assumes that biofuel production, processing and transport are matters of public

Table 1. A broad typology of biofuel sustainability frameworks and certification schemes by governance level and adoption requirements

\begin{tabular}{lll}
\hline Governance level & Voluntary & Mandatory \\
\hline International & RSB & \\
& RSPO & \\
RTRS & BSI & \\
& FSC & EU RED \\
Supranational/regional & & $\begin{array}{l}\text { Renewable Transport Fuel Obligation (UK) } \\
\text { National }\end{array}$ \\
& $\begin{array}{l}\text { Nordic Ecolabel } \\
\text { Verified Sustainable Ethanol Label } \\
\text { (SEKAB, Sweden) }\end{array}$ & $\begin{array}{l}\text { German Biofuel Quota Act (Germany) } \\
\text { Swiss Petroleum Tax Act (Switzerland) }\end{array}$ \\
\hline
\end{tabular}

BSI = Better Sugarcane Initiative, EU RED = European Union Renewable Energy Directive, FSC = Forest Stewardship Council, RSB $=$ Roundtable on Sustainable Biofuels, RSPO = Roundtable on Sustainable Palm Oil, RTRS = Round Table on Responsible Soy Association

Note: The six sustainability frameworks examined in this report are RSB, RSPO, RTRS, BSI, FSC and EU RED. Others are included for reference. It should be noted that the only mandatory aspects in the EU RED relate to accounting rules for greenhouse gas emissions and other requirements such as 'no-go' areas. In addition, the EU RED can be implemented through bilateral agreements, voluntary certification schemes or national requirements. 
interest and, as such, must be managed by the state. In such cases, national laws or executive authorities empower regulatory bodies to establish criteria and standards on the sustainability of biofuels, to issue norms and quotas, and to verify the registration of producers and industrial facilities. This is, in short, a national legislative approach to implementing and monitoring sustainability frameworks, with the government bearing the associated costs, and the country's ability to carry it out depending on its capacity for monitoring and law enforcement. In the context of producer and consumer countries, this approach may be implemented through bilateral agreements.

The second approach assumes that biofuel production, processing and transport can be managed through market-based schemes linked to voluntary adoption of defined production standards and accompanying certification. For certification, an independent party evaluates the production process against a set of predetermined standards. A key feature of this approach is that the producer is responsible for covering costs and proving compliance; therefore, the producer decides whether to comply and with which standard. Even if a certain market, for example the EU, sets mandatory sustainability standards, the producer can choose to sell to a different market with no such requirements. ${ }^{1}$

A possible third approach is a combination of legislative and voluntary market-based approaches, in which governments may set national mandatory standards for biofuel sustainability and require producers to comply via third-party certification.

Of the six frameworks analysed in this report, only the FSC standard is not strictly related to biofuel feedstock production, processing and trade. The EU RED and RSB have a strict biofuel focus, whereas the others have a commodity-specific focus (palm oil, soybean, sugar or timber) addressing the food, fibre and biofuel applications of the crop. In contrast to the biofuel frameworks, the FSC is well established, with a long history of projectlevel applications, which means it is useful for

1 In the case of the EU market, the producer can even sell to the EU, but it will not count towards the renewable energy targets established in the EU RED. comparison. The FSC standard is also considered relevant in this context because of its potential to serve as a framework for certifying the production of second generation biofuels from short-rotation tree plantations. How the FSC framework is ultimately applied may largely depend on whether it can be adapted to comply with essential criteria such as minimum lifecycle GHG reductions and issues of LUC, aspects that are underdeveloped in the current version of the standard. ${ }^{2}$

Other certification systems have been developed for the agriculture sector but they are not related to biofuel production per se (however, some lessons drawn from these could help to advance sustainable biofuel production in the future). For instance, EUREPGAP, a partnership between producer and retailer associations, focuses on good agricultural practices, quality management, minimisation of negative environmental impacts of crop production and track-and-trace control. The Sustainable Agriculture Network (SAN) was formed by conservation groups, mostly NGOs, to promote the social sustainability of products that are safe and healthy for the consumer, and are obtained in an environmentally sustainable way. The International Federation of Organic Agriculture Movements (IFOAM) works on promoting the adoption of agricultural sustainability standards based on organic production. Also not included here are the eight environmental indicators of the Global Bioenergy Partnership (GBEP) which are largely intended to guide decision making on a generic level and which are considered a work in progress. ${ }^{3}$ These are briefly discussed however, in the context of efforts to develop uniform sustainability standards (Section 4.1).

2 Other forest-based sustainability frameworks, which are not analysed in this report, include the Finnish Forest Certification System (FFCS), Chile's CERFOR and Brazil's CERTIFOR. In addition, the expansion of national forest certification systems has led to the creation of the Programme for the Endorsement of Forest Certification (PEFC) for the assessment and mutual recognition of national forest certification schemes; the PEFC now covers more than 20 national schemes.

3 http://www.globalbioenergy.org/fileadmin/user_ upload/gbep/docs/2011_events/11th_TF_Sustainability_ Stockholm_15-17_March_2011/indicators/names_and_ descriptions.pdf. 


\subsection{European Union Renewable Energy Directive}

The European Union 2009 Renewable Energy Directive (EU RED) ${ }^{4}$ sets an overall EU target for renewable energy of $20 \%$ of total energy consumption by 2020 . This translates into binding national targets for member states, with each member state required to achieve individual national targets for renewable energy. In addition, all member states must achieve a renewable energy target of $10 \%$ of the transport sector. In this context, 'renewable energy' includes not only biofuels but also biogas and electricity derived from sources certified as renewable, including solid biomass, wind, solar and hydropower. For a biofuel to count towards these targets, it must comply with the EU's sustainability requirements. ${ }^{5}$ In particular, to comply with the EU RED, raw materials for biofuels must not have been cultivated on primary forests and other wooded land, areas designated for the protection of rare, threatened or endangered ecosystems or species, or highly biodiverse grassland. Furthermore, to be eligible, biofuels must not be made using material extracted from peatland or land with a high carbon stock, such as wetlands, continuously forested areas and land covered by trees taller than $5 \mathrm{~m}$ with a canopy cover of $10-30 \%$.

In 2010, the EC adopted a package of two communications and one decision, with the following main points: ${ }^{6}$

4 Directive 2009/28/EC of the European Parliament and of the Council of 23 April 2009 on the promotion of the use of energy from renewable sources and amending and subsequently repealing Directives 2001/77/EC and 2003/30/ EC. http://eur-lex.europa.eu/LexUriServ/LexUriServ.do?uri=O J:L:2009:140:0016:0062:EN:PDF.

5 The EU RED is unique in that its sustainability requirements can be met through bilateral agreements with producer nations and hence can be based on national rather than project-level principles.

6 The 'Communication on voluntary schemes and default values in the EU biofuels and bioliquids sustainability scheme', the 'Communication on the practical implementation of the EU biofuels and bioliquids sustainability scheme and on counting rules for biofuels' and the 'Decision on guidelines for the calculation of land carbon stocks' are available at http://ec.europa.eu/energy/renewables/biofuels/ sustainability_criteria_en.htm. See also http://europa.eu/rapid/ pressReleasesAction. do ?reference $=M E M O / 10 / 247 \&$ format $=H$ TML\&aged $=0$ \&language $=\mathrm{EN} \&$ guiLanguage $=\mathrm{en}$.
Sustainable biofuel certificates. The EC encourages industry, governments and NGOs to set up 'voluntary schemes' to certify biofuel sustainability. The communication explains the standards required to gain EU recognition. One of the main criteria for certification schemes is that they have independent auditors, which evaluate the entire production chain, from the farmer to the conversion facilities, to the trader, to the fuel supplier that delivers petrol or diesel to the filling station. The communication sets standards requiring this auditing to be reliable and fraud resistant.

Protection of undisturbed natural areas. The communication highlights that biofuels should not be made from raw materials from tropical forests or recently deforested areas, drained peatland, wetland or highly biodiverse areas. It also sets out guidelines for assessing whether this is the case. It explicitly prohibits the conversion of forest for oil palm plantations.

\section{Promotion only of biofuels with high GHG} savings. The communication reiterates that member states must meet binding national targets for renewable energy, and that only biofuels with high GHG savings can count towards the national targets. It explains how to calculate such savings. To be eligible, biofuels must deliver GHG savings of at least 35\% compared with fossil fuels, rising to $50 \%$ in 2017 and to $60 \%$, for biofuels from new processing facilities, in 2018.

There are three ways of complying with the EU RED: 1) provide evidence of compliance with the national system of the member state where the biofuels are being used; 2) refer to a voluntary scheme that has been approved by the European Commission or 3) meet the terms of a bilateral or multilateral agreement approved by the EC. For criteria related to GHG emissions, data should include evidence of compliance with member state procedures or application of the default values in the EU RED. Economic operators must use the mass balance system to prove that feedstocks for biofuels were sourced in a way that meets the criteria. Under this system, the share of material that is certified as sustainable is tied to the respective shares of the final products made from the raw materials. The mass balance system is less 
stringent than 'identity preservation', in which certified feedstock materials must be physically isolated from noncertified feedstocks. However, the mass balance system used in the EU RED is more stringent than the 'book and claim' system, which is used elsewhere for renewable energy quotas and GHG emissions trading. Sustainability certificates are generated for the certified feedstock; these can then be sold to any biofuel producers that wish to use these feedstocks. The EC, recognising that the mass balance system is more complex and expensive than the book and claim system, has advised that it will reconsider the requirement to use mass balance in its next report in 2012 .

\subsection{Roundtable on Sustainable Biofuels}

The Roundtable on Sustainable Biofuels (RSB) was established in 2007 to develop international sustainability standards through dialogue between conservation and development organisations, the private sector and academia. It is the only biofuel standard that covers the entire value chain, from farm to end user. Version two of the RSB standard sets out 12 principles and associated criteria for sustainable biofuel production along with guidance and compliance indicators. ${ }^{7}$ The 12 principles and criteria address: 1) legality; 2) planning, monitoring and continuous improvement; 3 ) greenhouse gas emissions; 4) human and labour rights; 5) rural and social development; 6) local food security; 7) conservation; 8) soil; 9) water; 10) air; 11) use of technology, inputs and management of waste; and 12) land rights. The RSB has also developed guidance for conducting an environmental and social impact assessment, including social guidelines, ecosystem and conservation values, and soil and water guidelines. Two approaches are being examined to address indirect impacts: 1 ) the use of an indirect LUC factor and 2) promotion of practices and feedstocks that lower the risk of indirect negative impacts.

In 2010, the RSB developed a GHG accounting methodology that draws on the Intergovernmental Panel on Climate Change (IPCC) guidelines. It refers to the use of co-products, residues and waste and may include indirect LUC. The RSB has

7 Available at http://rsb.epfl.ch/page-24929-en.html. set a minimum GHG emission threshold of 50\% for biofuel blends compared with the fossil fuel baseline; this threshold will be increased over time. The standard also requires each biofuel in the blend to have lower lifecycle GHG emissions than the baseline.

The RSB has adopted a 'meta-standard' approach to certification. 8 The RSB biofuel certification standard is expected to become fully operational in 2011. The RSB has developed a standard for EU market access, which in July 2011 was adopted as a way to demonstrate and document compliance with the EU RED.

\subsection{Roundtable on Sustainable Palm Oil}

The Roundtable on Sustainable Palm Oil (RSPO) is a global, multistakeholder initiative that promotes the production and use of sustainable palm oil products. ${ }^{9}$ The RSPO principles and criteria were adopted at the end of 2007 and focus primarily on the agricultural or feedstock production side (i.e. they do not fully cover transport and processing). A methodology and set of guidelines are available for national interpretation of the RSPO principles and criteria. The RSPO principles are based on: 1) commitment to transparency; 2) compliance with applicable laws and regulations; 3 ) commitment to long-term economic and financial viability; 4) use of best practices by growers and millers; 5) environmental responsibility and conservation of natural resources and biodiversity; 6) responsible consideration of employees, individuals and communities; 7) responsible development of new plantings; and 8) commitment to continuous improvement in key areas. The RSPO intends to prepare a common framework for reporting, as well as a methodology for the certification of emission reductions. It will propose methods to reduce GHG emissions, particularly related to LUC, including planting on degraded land, increasing yield and investigating ways to reduce emissions from peatlands.

8 A 'meta-standard' defines what is considered sustainable through principles and criteria; however, compliance requires certification under existing standards, which in turn ensure that the principles and criteria of the meta-standard are complied with.

9 http://www.rspo.org/. 


\subsection{Round Table on Responsible Soy Association}

The Round Table on Responsible Soy Association (RTRS) was established in $2006 .{ }^{10}$ The RTRS standard was released in 2010 and contains five principles: 1) legal compliance and good business practice; 2) responsible labour conditions; 3 ) responsible community relations; 4) environmental responsibility; and 5) good agricultural practice. These principles form the foundations for norms to be used within a voluntary certification system for soybean production. Certification in each country is based on national interpretation of the principles and criteria, built on the Guidance for National Interpretation developed by the RTRS. National interpretations of the RTRS generic standard define applicable local indicators, guidelines or procedures for economic, social and environmental aspects adapted to local circumstances. The RTRS is also expected to develop national-level maps that will provide biodiversity information, as well as a system to guide responsible expansion of certified soya. A voluntary RTRS certification scheme will be developed in compliance with the EU RED. Operational procedures are yet to be developed for the supply chain certification and the supply chain traceability scheme.

\subsection{Better Sugarcane Initiative}

The Better Sugarcane Initiative (BSI or Bonsucro) sustainability framework includes principles and criteria for sustainable sugarcane production and the Chain of Custody Standard. ${ }^{11}$ The BSI standard includes a set of technical and administrative requirements for tracking along the entire supply chain for all sugarcane products. The BSI standard includes the following principles: 1) obey the law;

2) respect human rights and labour standards;

3) manage input, production and processing efficiencies to enhance sustainability; 4) actively manage biodiversity and ecosystem services; and 5) commit to continuous improvement in key areas of the business.

The BSI has proposed a scheme for calculating GHG emissions from sugarcane cultivation,

10 http://www.responsiblesoy.org/.

11 http://www.bonsucro.com/. processing to sugar and/or ethanol, and direct LUC. Emissions released from indirect LUC are not included, as the methods and data requirements are not available. Default and secondary data (defined as being generated from other sources) are proposed for calculating emissions where actual data are not available.

The BSI has also developed guidance documents for certification, including recommendations on the interpretation of the principles and criteria and the requirements to ensure compliance. As with many other schemes, the BSI recently submitted an application to the EU for recognition as a voluntary scheme; if granted, this will allow sugarcane ethanol importers in the EU to use the BSI to show compliance with the EU RED from 2011 onwards.

\subsection{Forest Stewardship Council}

The Forest Stewardship Council (FSC) is an independent, nongovernment and non-profit international organisation founded in 1993 to globally promote sustainable forest management that is environmentally appropriate, socially beneficial and economically viable. ${ }^{12}$ The members of the FSC make up a general assembly, which serves as its highest decision making body; it has a tripartite structure covering social, environmental and economic aspects (chambers).

The FSC developed a global sustainability framework for its definition of well managed forests; the framework includes 10 principles and 56 criteria related to: 1) compliance with applicable laws and international treaties; 2 ) long-term tenure and use rights and responsibilities; 3 ) indigenous peoples' rights; 4) social well-being and respect for workers' rights; 5) equitable benefit sharing; 6) reduction of environmental impact; 7) forest management plans; 8) monitoring and assessment; 9) maintenance of high conservation value forests; and 10) tree plantations. These principles and criteria are tailored to conditions in different countries.

Using the FSC label requires chain of custody certification, which involves tracking forest products all along the supply chain and

12 http://www.fsc.org/. 
guaranteeing that products meet specific content requirements. Audits are conducted by independent certification bodies. As woody biomass is likely to become a feedstock with the development of second generation biofuels, the FSC scheme remains valid for woody biomass production and it may gain further relevance. Of special relevance for the biofuel sector is FSC Principle 10 on establishment of tree plantations; however, the FSC does not yet have a specific policy on woody biomass used for biofuels.

Whereas the other sustainability frameworks analysed in this report are all quite new, the FSC was established almost 20 years ago. Therefore, a substantial amount of information on its performance and effectiveness is available (see Auld et al. 2008 and references therein). The area of FSC certified forests is about 140 million ha, across 82 countries; although primarily in temperate and boreal latitudes, nearly 9 million ha is located in tropical countries. Nevertheless, FSC certification has reportedly made only a modest contribution to reducing deforestation at the global level since the first FSC certificate was issued about 15 years ago (Marx and Cuypers 2010). It should be noted, however, that the FSC standard was not explicitly designed to halt deforestation at the country level. It has also been shown that certification is often unattainable for small and medium-sized enterprises in developing countries, as these cannot meet the high costs involved (Auld et al. 2008). The FSC is therefore contemplating group certification and certification of small-scale and low intensity forest operations, designed to overcome such financial and technical constraints. 


\section{Environmental issues in sustainability frameworks}

S ections 3.1 and 3.2 provide a comparison of the frameworks in terms of key environmental issues: biodiversity, soil, water and environmental impacts, and LUC and related GHG emissions. Tables 2 and 3 provide an overview of the main comparisons, which form the basis for the more detailed analysis in Section 3.3 of identified gaps.

\subsection{Biodiversity, soil, water and environmental impacts}

Biofuel production, transport and consumption has been challenged over its possible negative impacts on soil and water conservation, air quality, biodiversity, and on GHG emissions from direct and indirect LUC. All six frameworks examined in this report include criteria related to areas with significant biodiversity that are not under official protection. Most of the frameworks also include criteria related either to the need to protect or restore native ecosystems in order to reduce the impacts of the conversion of forest or natural habitat in order to cultivate biofuel feedstocks. All frameworks emphasise the conservation of areas of significant biodiversity value as well as native ecosystems and natural habitats wherever possible (Table 2). Furthermore, all frameworks prohibit conversion of high conservation value (HCV) areas for biofuel feedstock production. The RSPO considers HCV areas as 'no go', while the FSC, RTRS, BSI and RSB authorise limited exploitation of $\mathrm{HCV}$ areas so long as the HCV is maintained.

The EU RED sustainability framework requires that land with high biodiversity value (highly biodiverse grasslands, primary forests and nature protection areas) or high carbon stock (wetlands, peatland and forested areas that also harbour significant biodiversity) is not used for biofuels and bioenergy production. For biomass feedstock produced in the EU, the EU RED accepts the crosscompliance rules of the Common Agricultural Policy as providing assurance of compliance in relation to environmental impacts on soil, water and air (Table 2). The RTRS plans to develop national-level biodiversity maps. Some frameworks (BSI, RTRS, RSPO, RSB) refer to international conventions such as the Convention on Wetlands (Ramsar Convention), Convention on Biological Diversity, the Rotterdam Convention on pesticides and industrial chemicals and the Stockholm Convention on Persistent Organic Pollutants. With the exception of the EU RED and the FSC, all the frameworks give due consideration to ecological connectivity, which is an integral part of land use planning for conservation purposes (see Section 3.3.1). In the context of second generation biofuels, which could involve genetic manipulation of woody plants for disease resistant plant traits or enhanced production of lignocellulose (Hetemäki et al. 2010), the FSC prohibits the use of genetically modified organisms.

The sustainability frameworks adopt different approaches to addressing environmental impacts. Some require an environmental impact assessment, as defined by the relevant legislation in force, or good farming practices. For example, the RSB provides guidance for conducting an environmental and social impact assessment, including soil, water, social and land rights guidelines. The RTRS 
Table 2. Environmental issues in the six biofuel sustainability frameworks

\begin{tabular}{|c|c|c|c|c|c|c|}
\hline & EU RED & RSB & RSPO & RTRS & BSI & FSC \\
\hline Environmental impact assessment & - & + & + & + & + & + \\
\hline Good farming practices & + & + & + & - & + & + \\
\hline Mitigation of indirect LUC or indirect impacts & - & + & - & + & - & - \\
\hline Use of degraded lands & + & + & + & + & - & - \\
\hline $\begin{array}{l}\text { Conservation of unprotected areas of significant } \\
\text { biodiversity value and HCV areas }\end{array}$ & + & + & + & + & + & + \\
\hline Conservation of natural ecosystems & + & + & + & + & + & + \\
\hline Ecological corridors, riparian areas & - & + & + & + & + & - \\
\hline Genetically modified organisms & - & + & + & - & + & + \\
\hline Conversion of forest/natural habitat & + & + & + & + & + & + \\
\hline Soil management and soil protection & - & + & + & + & + & + \\
\hline Use of agrochemicals & - & + & + & + & - & - \\
\hline Use of waste and residues & + & + & + & + & + & - \\
\hline No burning during land clearing & - & - & + & - & - & - \\
\hline Conservation of above- and below-ground carbon & + & + & + & - & + & - \\
\hline Calculation of GHG emissions from direct LUC & + & + & + & + & + & - \\
\hline Calculation of GHG emissions from indirect LUC & - & - & - & - & - & - \\
\hline
\end{tabular}

BSI = Better Sugarcane Initiative, EU RED = European Union Renewable Energy Directive, FSC = Forest Stewardship Council, GHG $=$ greenhouse gas, $\mathrm{HCV}=$ high conservation value, $\mathrm{LUC}=$ land use change, RSB $=$ Roundtable on Sustainable Biofuels, RSPO = Roundtable on Sustainable Palm Oil, RTRS = Round Table on Responsible Soy Association

Note: ' + 'indicates that the issue is explicitly addressed (either with or without enough guidance for its implementation). ' indicates that the framework contains little or no specific mention of the issue.

Source: Adapted from Henneberg et al. (2010) and Scarlat and Dallemand (2011)

includes integrated crop management measures and practices in soya production, and the BSI provides guidance for setting up an environmental management plan. The FSC requires an assessment of environmental impacts appropriate to the scale, management intensity and the uniqueness of the affected resources - including landscapelevel considerations, as well as the impacts of onsite processing facilities. Issues related to access to and management of fresh water resources are underdeveloped in the reviewed standards particularly as they relate to competition for water with food crops.

\subsection{Land use change (direct and indirect) and associated greenhouse gas emissions}

The potential conversion of large expanses of native forests for biofuel plantations is a major concern in the biofuel debate. Therefore, assessing the extent to which biofuel projects are causing deforestation, or LUC, or seeking to reduce the risk of deforestation should be key goals in sustainability frameworks. LUC is particularly relevant because of its implications for the provision of numerous environmental benefits such as biodiversity, soil and water conservation and GHG emission reductions.

Assessing the LUC impacts of a specific biofuel project is not easy, particularly for indirect LUC, because of the lack of standard definitions of deforestation and even 'forests', the simultaneous use of biofuel feedstocks for food, feed and/or fuel and the geographical disconnect between where planting and deforestation occur, among other factors (Gao et al. 2010). The sustainability frameworks only address direct LUC, essentially by limiting the type of land on which biofuel projects may be established.

Concerns about LUC and GHG emissions are closely linked. For global GHG emission targets to be met, biofuels must make a significant 
contribution to reducing emissions, particularly by avoiding deforestation. This objective can be easily translated into criteria and quantitative indicators that set out certain levels of emission reductions. ${ }^{13}$ For this reason, in most frameworks, deforestation is treated implicitly through statements on specific targets for GHG emission reductions, which in practice imply that no LUC is involved. Below we review in detail how each framework treats LUC issues (see also Table 3).

The EU RED attempts to minimise emissions due to direct LUC by restricting which types of land can be used to produce biofuel feedstocks. Lands that cannot be used to produce biofuels include 1) primary forest and other wooded land (to protect biodiversity and prevent carbon stock losses); 2) wetlands (which can have extremely high carbon stocks); 3) continuously forested areas, defined as land of more than 1 ha with trees taller than 5 $\mathrm{m}$ and a canopy cover of more than $30 \%$, or trees able to reach those thresholds in situ; and 4) land of more than 1 ha with trees taller than $5 \mathrm{~m}$ and a canopy cover of $10-30 \%$, or trees able to reach those thresholds in situ, unless evidence is provided that the amount of carbon stock of the area before and after conversion fulfils certain requirements (both (3) and (4) are included because carbon stock losses must be considered in GHG emission estimates) (Table 3).

The RSB does not include a specific LUC criterion. However, its Principle 3 addresses GHG emissions, and states that (the RSB) lifecycle assessment methodology should be used. This includes emissions due to stock changes in above- and below-ground dead organic matter and soil organic carbon from conversion of natural or managed ecosystems to cropland for bioenergy feedstock production only, using an IPCC Tier 1 type approach. As such, the RSB methodology is not designed for forests that remain forests (e.g. conversion of natural forest to oil palm plantation). Furthermore, the RSB methodology does not include indirect LUC. However, its Principle $3 \mathrm{~b}$ states that use of co-products, residues and wastes should be incentivised, a policy that could ameliorate indirect LUC.

13 However, calculating GHG emissions requires the use of lifecycle assessment, which has yet to be standardised.
The RSPO Principles and Criteria for Sustainable Palm Oil Production state that the 'RSPO will urgently establish a working group to consider all issues relating to Greenhouse Gas emissions, in terms of their relevance to the oil palm sector'. However, at the time of writing this report, the RSPO had not published any principles or criteria specifically addressing GHG emissions. The RSPO has not adopted the EU RED limitations on previous land use, but has considered imposing limitations on the average carbon stocks before conversion of land to oil palm plantations and the use of 'offsets' to sequester carbon if development of plantations generates emissions (Table 3).

The RTRS includes two criteria on GHG emissions and expansion of soya production. Criterion 4.3 mentions fossil fuel use, soil protection and opportunities for increasing carbon sequestration. However, it does not set a value as the limit of GHG emissions. In the context of 'responsible' soy cultivation, Criterion 4.4 of the RTRS states that cultivation should not be expanded into native forest, according to its definition. ${ }^{14}$ However, land that was cleared before May 2009 and had been used for agriculture within the previous 12 years can be used, unless native forest has been re-established through regeneration. In addition, soya cultivation should not be expanded into native vegetation. ${ }^{15}$ These conditions will limit the amount of GHG emissions due to direct LUC. However, the values used to define native forest are not aligned with the definition of forests in the United Nations Framework Convention on Climate Change (UNFCCC). ${ }^{16}$ This could create a situation where soya cultivation could expand 'responsibly' into non-native forest but still cause deforestation. For example, while the RTRS defines forests as areas with at least $35 \%$ crown cover and with at least some trees of $10 \mathrm{~m}$ in height, the government of Brazil has defined forests as containing trees of 5 $\mathrm{m}$ in height and with $30 \%$ crown cover. Therefore, a parcel of land that has trees with these latter

14 The RTRS defines native forests as 'areas of native vegetation of 1 ha or more with canopy cover of more than 35\% and where some trees (at least 10 trees per hectare) reach $10 \mathrm{~m}$ in height (or are able to reach these thresholds in situ [i.e. in that soil/climate combination])'

15 No definition of 'native vegetation' is provided.

16 Under the Kyoto Protocol countries must define a forest as having canopy cover of $10-30 \%$, height of trees at maturity (in situ) of $2-5 \mathrm{~m}$ (or the ability to reach this height) and a minimum size of $0.05-1.00$ ha. 
characteristics would be considered forest under the Kyoto Protocol but could still be deforested for 'responsible' soya expansion (Table 3).

The BSI adopts the one mandatory criterion in the EU RED (to protect land with high biodiversity value, land with high carbon stock and peatlands) to control the production source of sugarcane. The BSI also includes a non-mandatory criterion dedicated to GHG emissions. Criterion 3.2 limits GHG emissions to a specified amount per tonne of sugar or amount per megajoule (MJ) of ethanol produced ( $24 \mathrm{~g} \mathrm{CO}_{2}$-eq/MJ). This is more stringent than the EU RED, but the EU RED limit is mandatory. The calculation method is the same as that in the EU RED, which addresses only emissions from direct LUC.

The FSC does not address GHG emissions in its standard. However, FSC Principle 10 states that the design and layout of plantations should promote the protection, restoration and conservation of natural forests, and not increase pressure on them. More specifically, Criterion 10.6 says that 'diversity in the composition of plantations is preferred, so as to enhance economic, ecological and social stability. This runs counter to the establishment of highly productive monospecific stands, typical of biofuel operations. In addition, Criterion 10.9 states that 'plantations established in areas converted from natural forests after November 1994 normally shall not qualify for certification.

A comparison of the six sustainability frameworks reveals a lack of consensus on approaches to mitigating the impact of indirect LUC (Table 2). Four of the frameworks (EU RED, RSB, RTRS, RSPO) specifically mention the use of degraded lands for cultivation, and the EU RED gives a premium (doubling factor for the EU biofuel quota) to biofuel feedstocks produced on degraded land and also produced from crop residues and wastes. However, although the frameworks seek to ensure that bioenergy originates from raw material with a low risk of leakage - such as biomass cultivated on unused, degraded land or from organic wastes and crop residues - no standard specifically promotes land use planning or cultivation on abandoned or degraded land in order to mitigate leakage. Where frameworks do include mitigation systems, such systems are weak. Moreover, an operational definition of degradation has not been agreed upon at either national or international levels (FAO 2009, Guariguata et al. 2009). For the purposes of suitability of oil palm cultivation, 'degraded lands' can be defined as those with low levels of above ground carbon and biodiversity. ${ }^{17}$ None of the frameworks analysed here accounts for GHG emissions resulting from indirect LUC.

\subsection{Main limitations of the frameworks}

\subsubsection{Land use planning and best management practices}

As the frameworks and their standards are only a means to an end, they must be supported by practical guidance, effective interpretation of principles and criteria, and the provision of appropriate tools and approaches. For example, although most of the frameworks examined in this report refer to good farming practices, none explicitly addresses biodiversity issues in the context of production landscapes. Practices explored in the eco-agriculture literature provide many examples that can be adapted to any biofuel production operation (Scherr and McNeely 2007) including agro-ecological zoning and/or economic incentives that are linked to specific land use practices. As discussed above, even well-designed frameworks and their standards are not sufficient alone to mitigate direct and particularly indirect LUC. Therefore, frameworks and certification systems need to be complemented by other policy instruments (Hennenberg et al. 2010). Effective land use planning is potentially critical in this regard. None of the frameworks analysed in this report explicitly requires the development of new, highly productive cultivation systems (which would minimise further habitat land conversion). Should this issue be included in the future, however, sustainability frameworks may also have to be explicit about whether genetically modified organisms (GMOs) are to be used. The few frameworks analysed here that address the use GMOs are unclear in this regard.

17 For an example from Indonesia, see http://www.wri.org/ stories/2010/11/faq-indonesia-degraded-land-and-sustainablepalm-oil. 


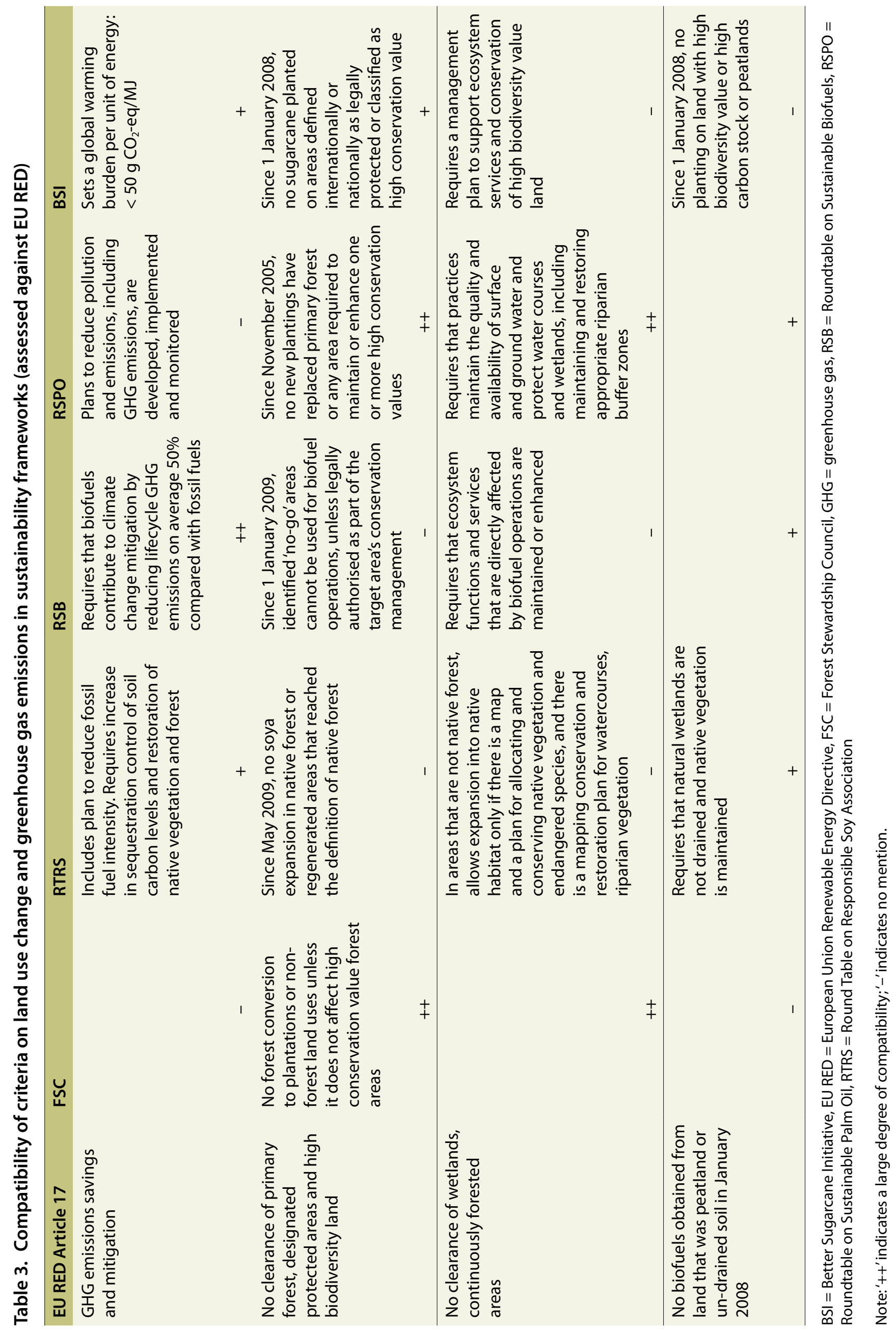




\subsubsection{Carbon stocks}

Bioenergy stakeholders often misunderstand the relationship between sustainability, carbon stocks and GHG emissions. In the context of the above discussion, 'sustainability' means production that ensures continuity without causing a depletion of natural resources, soil or water, as measured against a defined baseline. However, in the context of forests, the relationship between sustainability and carbon stocks is not straightforward. It is possible for two sustainably managed forests at the same site (and even with the same species) to have different carbon stocks. Even though both management systems are sustainable, the transition between systems can cause a change in carbon stocks and $\mathrm{CO}_{2}$ emissions or sequestration during the transition period. For example, increasing harvest rotations increases carbon stocks in the landscape while decreasing carbon in harvested wood products (Nabuurs et al. 2007). Thus, shortening harvest rotations temporarily decreases carbon stocks in the landscape.

A specific example is the conversion of unmanaged forests to oil palm plantations (Bird et al. 2010). Both the unmanaged forest and the oil palm plantation may be 'sustainable' but the transition can cause a carbon stock loss of more than 100 tonnes of carbon per hectare over more than 30 years. During the transition period, the activity is 'temporarily unsustainable'. It may therefore be necessary for biofuel sustainability frameworks to include a criterion on the transition of carbon stocks.

\subsubsection{Spatial scales}

Many environmental sustainability principles and criteria are of limited effectiveness because of the exclusive focus on the production unit at the 'farm' level. However, it is possible that a certified operation using production practices that are sustainable at the farm level may cause some form of harm - or undesirable effects - at landscape or regional levels, including the effects of indirect LUC. In essence, farm-level assessments do not consider the cumulative effects of multiple farmlevel impacts. This is the case for the conservation of biodiversity, water resources and soils, for example. In the case of water resources, the appropriate ecological unit for assessing impacts is probably at the watershed scale. Where a sustainability standard requires national legislation, applying land use planning decisions at the national or local level that are mandated by national legislation can mitigate some impacts (in this context the EU RED option of bilateral agreements is highly relevant). Frameworks such as the RSPO and RTRS have started to prepare national interpretations of their principles and criteria to ensure the implementation of certification at the country level, according to specific conditions.

Furthermore, threshold levels that are useful and/ or acceptable at the farm level can be insufficient or inadequate at larger scales. A good example is the Brazilian Forest Code, which states that in biomes other than cerrado and Amazonian forest, native plant cover must be retained on $20 \%$ of every property, although the remainder can be converted to other land uses. If the principle of legality is applied in the strictest sense, this legal provision is the only limit to LUC, thus allowing for the conversion of $80 \%$ of all lands, with sizable environmental impacts (e.g. on water cycle, biodiversity and soil conservation). Thus, a possible conflict exists between the principles of legality and environmental sustainability.

\subsubsection{Temporal scales}

Many ecological processes, such as climate change or soil degradation, occur over long periods. However, a 20-year span has been chosen in the EU RED and other frameworks as the standard timeframe for estimating (or discounting) the various possible impacts of biofuel production. This period was chosen on the assumption that feedstocks would come from agricultural sources. The main carbon stock in this case is soil organic carbon, and the simplified IPCC methodology (Tier 1) for calculating carbon stock changes from LUC assumes a 20 -year transition period. The transition period will be shorter for tropical situations and longer for temperate or boreal ecosystems. However, changes in land management and use, particularly involving forests, cause carbon stock changes that occur over longer periods. It has been suggested that a more appropriate timescale for estimation for sustainable forest systems is the first rotation (Bird et al. 2010). 


\subsubsection{Compliance in the context of weak local capacity}

A major limitation of the sustainability frameworks analysed in this report is that their implementation in developing countries is difficult because of differences in goals, local capabilities and certification costs. In terms of goals, the EU RED standard aims especially at avoiding LUC and ensuring climate mitigation - a goal that, according to the UNFCCC, is considered an obligation of the developed world because of historical GHG emissions. Similarly, most frameworks promote GHG emissions savings, which, although important, are not the responsibility of developing countries. Developing countries, however, are actively pursuing biofuel production because of the sector's potential contribution to rural and socioeconomic development and may be difficult for these countries to fully comply with environmental standards including those of the EU RED.

Local capabilities (e.g. to effectively monitor compliance) could also affect developing countries' ability to meet the complex requirements of the voluntary schemes or the EU RED. Consequently, institutional weaknesses may prevent developing countries from exploiting their comparative advantage in biofuel production, which arises largely from favourable tropical climates and relatively low labour costs. The high biomass productivity in tropical and subtropical climates allows for a better energy balance and lower GHG emissions with respect to temperate latitudes (El Bassam 2010) as in the case of sugarcane and ethanol production in Brazil (Smeets et al. 2006). More importantly, some least developed countries (LDCs) are viewed as risky locations with respect to fulfilling or enforcing biofuel sustainability frameworks. Domestic and international investors may perceive LDCs as unlikely to gain access to the EU market, and thus will not even consider them for investment, despite their high production potential and competitiveness (Johnson 2011).

The costs of biofuel sustainability certification should not necessarily become a barrier per se; they have been estimated at less than 0.5 euro/ tonne of carbon (EC 2008) or approximately 0.001 euro/litre. However, these estimated costs are based on European conditions, whereas the costs in developing countries would likely be much higher, particularly compared with local incomes. Furthermore, biofuel certification processes would impose high transaction costs because of the lower administrative and technical capacities in developing countries and because of weak institutional capacity.

The bioethanol produced in Brazil is an example of a biofuel that easily satisfies the EU RED criteria. However, Brazil's bioethanol industry was initially developed to achieve policy goals related to energy security, import substitution and economic development. Climate change mitigation and environmental quality improvements (including air) were added later as an extra benefit (Macedo 2005). The constraints imposed on developing countries by most of the sustainability frameworks analysed in this report suggest that some complementary measures will be needed to better assess key environment-development linkages and thus exploit synergies and avoid conflicts. In other words, greater effort is needed in the context of global and regional policy to insure that the development impacts of biofuel production are weighed alongside climate impacts. 



\section{Improving biofuel sustainability frameworks: Key issues and challenges}

\subsection{Integration and harmonisation}

As this review demonstrates, biofuel sustainability frameworks have very different formulations of environmental criteria and definitions (e.g. regarding the areas to be protected). However, views differ as to whether a globally harmonised sustainability framework would be broadly applicable or appropriate. On the one hand is the argument that in an era of global trade, the global market will inevitably induce the full emergence of international frameworks and/or certification systems (Scarlat and Dallemand 2011). Kaditi (2009) concludes that because specific frameworks tend to be misused and misinterpreted, an international certification standard is perhaps the only instrument that could make a difference. Schubert and Blasch (2010) further point out that only an international, legally binding biofuel sustainability standard will prevent exporting countries from diverting their bioenergy exports to countries that have weak or non-existent minimum import standards, with the associated negative environmental consequences.

On the other hand, Mol (2007) argues that harmonisation, standardisation, certification and globalisation of biofuel pathways may end up empowering the largest and better organised actors, or favour developed countries at the expense of developing countries. Developed countries have historically been deforested and, in the context of agricultural expansion alone, their agricultural land area has decreased substantially over the years (Gibbs et al. 2010). This means they are less strongly bound by their own deforestation concerns. In addition, the cost of certification tends to be lower in developed countries (including FSC certification - see Marx and Cuypers 2010), which already possess the necessary technical and technological capabilities to undertake the more stringent production practices.

Buchholz et al. (2009) further add that a single fixed set of sustainability criteria and indicators might not be advisable for bioenergy systems; rather, they advocate for flexible biofuel sustainability assessments that can be adapted to different spatial and temporal scales. Hennenberg et al. (2010) also believe that it would be naive to think that biofuel sustainability frameworks could (or should) adopt a uniform set of criteria because each standard seems to serve at a specific stage of the production chain and for a particular feedstock. Although van Dam et al. (2008) caution against allowing biofuel sustainability frameworks to proliferate, they nevertheless argue that attempts to develop a global certification system may in fact lead to complications because of differences between regions in terms of production systems, spatial scale, socioeconomic settings and degrees of environmental sensitivity and conservation value. NGOs and civil society may be better equipped to assess whether greater compliance is achieved through a global standard or through many separate frameworks. Regional approaches to biofuel certification may in fact be more appropriate than either national or global approaches as they may have greater economic flexibility than national schemes while incorporating regional development objectives (see Section 4.2). In any case, how a 
global standard is to be crafted, if at all, remains uncertain. Schubert and Blasch (2010) propose a minimum standard with eight components; the Global Bioenergy Partnership considers a set of 24 global sustainability indicators spread across the environmental, social and economic dimensions of biofuel production, processing and transport (see Box 1).

Another potential restriction on developing a global framework is the geographical concentration of existing biofuel industries based on agricultural feedstocks. For example, the USA and Brazil account for a significant percentage of the global ethanol output, and Brazil and India are the world's two largest sugarcane producers. A similar geographical imbalance exists for biodiesel production, with Europe accounting for around $75 \%$ of the total output (Solomon 2010). However, the potential for trade surplus must also be considered, rather than just total output: India and the USA are unlikely to ever have a surplus, whereas Brazil and other countries with high potential and low population density can achieve a surplus of biofuels for international trade (Johnson 2011). Supranational initiatives such as the EU RED may have far-reaching implications because of their explicit reference to imported biofuels and respective feedstocks from suppliers anywhere across the globe. To date, bilateral agreements

\section{Box 1. Proposals for a uniform (minimum) set of biofuel standards}

From Schubert and Blasch (2010):

- Reduction in lifecycle greenhouse gas emissions;

- Avoidance of indirect land use change;

- Prohibition of use of biomass feedstock cultivated on land with high carbon stocks;

- Maintenance of soil quality and fertility through reduced use of agrochemicals;

- Conservation of forest ecosystems;

- Sustainable management of water resources;

- Control of use of genetically modified organisms;

- Compliance with basic social standards.

From Fritsche et al. (2011):

- Sustainable resource use (land use efficiency, secondary resource use efficiency);

- Biodiversity (conservation of land with high biodiversity value, biodiversity-friendly agricultural practices);

- Climate protection (lifecycle greenhouse gas emissions from direct and indirect land use change);

- Soil quality (avoidance of erosion, maintenance of soil organic carbon);

- Water use and quality (availability, use efficiency, quality);

- Airborne emissions ( $\mathrm{SO}_{2}$, particulates);

- Food security (availability and affordability of food);

- Social use of land (secure land access, land tenure);

- Healthy livelihoods and labour conditions (adherence to International Labour Organization principles for labour rights).

From the Global Bioenergy Partnershipa (2011):

- Lifecycle greenhouse gas emissions;

- Soil quality;

- Harvest levels of wood resources;

- Emissions of non-greenhouse gas air pollutants;

- Water use and efficiency;

- Water quality;

- Biological diversity in the landscape;

- Land use and land use change. 
between exporting and importing countries are the norm (Schubert and Blasch 2010).

As is illustrated in Box 1, no clear consensus has been reached regarding which criteria and indicators are critical and should be included for all circumstances, or which framework should become the global or international standard. A further complication is that the leading biofuel feedstocks clearly differ in their short- and longterm ecological impacts (Groom et al. 2008). Nevertheless, there is scope for developing a generic set of criteria, as some common key issues and/or indicators are emerging (Box 1). Ideally, standards would remain flexible with regard to geographical origins, raw materials and conversion technologies, as well as the different levels of chemical inputs and soil degradation encountered in the context of planting biofuel crops on degraded lands. As the impacts of land expansion for fuel and food crops are virtually indistinguishable from each other, it could also be argued that equal or uniform standards should be applied for all agricultural commodities traded internationally. Nevertheless, harmonising biofuel sustainability frameworks is perhaps more likely to be achieved by moving away from the criteria and indicator approach and promoting the adoption of international standards such as those of the International Organization for Standardization (ISO) (discussed in sections 4.2 and 4.3).

\subsection{Moving beyond principles, criteria and indicators}

That a set of principles, criteria and indicators (PCI) has the power to drive sustainability in biofuel production, transport and processing is not disputed. However, it is not the only solution to all potential sustainability problems. We discuss this issue using the EU RED framework and the implications of certification schemes from a European perspective.

The EU RED is a mandatory compliance scheme at the level of the importing (market) country. This is a very different concept from a market-based approach (such as the FSC), which targets final consumers. These two variants are by no means the only spheres in which PCI can be used to drive sustainable biofuel development. Individual producer countries can develop their own country specific set of PCI, as in the case of Mozambique (Sapp 2010). In such cases, compliance with PCI may be achieved through legislative processes, fiscal incentives or market-based incentives when applied to local markets. For instance, the Brazilian 'social seal', which requires that a proportion of feedstock comes from small-scale farmers, triggers tax rebates to reward compliance. The Southern African Development Community (SADC) has developed a set of principles for the SADC region. ${ }^{18}$ These principles are more likely to function as guidelines for member countries than as mechanisms for punishing bad or rewarding good practice. In addition, companies can implement their own set of environmental standards against which they are externally audited. The ISO 14000 set of standards is extensively used in the forestry industry for this purpose (Scheppers 2010, Scarlat and Dallemand 2011). A fundamental principle of the ISO approach is continuous improvement, in contrast to a PCI approach that usually seeks compliance from the outset. However, the EU RED creates a unique environment for implementing a PCI approach because it is an obligatory requirement for European Union countries growing or importing biofuels intended to meet national blending targets. In many ways, a mandatory scheme should have greater power to engender sustainability practices, but it could also have negative consequences in terms of diverting unsustainable biofuel production to alternative uncertified markets (see 4.3.1)

(Vis et al. 2008).

\subsection{Limitations of principles, criteria and indicators}

\subsubsection{Diversion to alternative markets}

Preferential market access, even if it is not accompanied by preferential price, is seen in the forestry industry as a key motivation for seeking certification (Cashore et al. 2005). In the case of forestry certification, final consumers create the market pull by preferentially purchasing certified products on a voluntary basis. This has been sufficient to prompt many forestry plantations to seek certification, and certified forests account

18 See http://www.probec.org/fileuploads/fl04142010091932_ SADC_Framework_for_Sustainable_Biofuels.pdf. 
for a large percentage of forests in some countries (Marx and Cuypers 2010). However, generally, certification has been sought for forests in developed countries and plantation forests rather than for tropical forests (Cashore et al. 2005). In addition, large quantities of tropical hardwood are sold to countries that have a low level of demand for certification.

Many developing world biofuel investors view Europe as a major market for biofuels. If alternative markets that are less concerned about sustainability issues develop, then non-compliant projects might export to these alternative markets. The EU's obligatory certification might even encourage the diversion of developing world biofuels to other markets. This could occur at the country level, with only some countries aiming to meet EU market requirements, or at the project level, where 'good' projects get certified and the others seek alternative markets (Vis et al. 2008).

Maintaining certification is costly (Zarrilli and Burnett 2008) and so a slight price premium might not be sufficient to attract producers to the certified markets. Producer country sustainability frameworks and joint agreements between the EU and producer countries are among the mechanisms to help alleviate this problem. It will, however, be necessary to rely on mechanisms other than certification, such as national mandatory standards, to ensure compliance with criteria at the country level rather than simply at the project level. Globally accepted frameworks and their standards and a global requirement to adhere to these are two mechanisms for overcoming this potential obstacle. An alternative mechanism would be for each individual country to ensure the compliance of all biofuels it produces.

\subsubsection{Violation of free trade agreements}

A subject of extensive debate is whether EU RED frameworks might violate some provisions of the World Trade Organization (WTO) (Zarrilli and Burnett 2008). The General Agreement on Tariffs and Trade (GATT) mandates equal treatment of products that are the same in physical terms, that is, 'like' products. Sustainable and non-sustainable biomass and biofuels cannot be distinguished from a product or market perspective at the point of end use, so the introduction of mandatory sustainability criteria could be regarded as non-conformant (see Echols 2009 and Vis et al. 2008). There is some scope through GATT for giving preference to products that are more environmentally friendly; however, the sustainability criteria may also be construed as constituting Technical Barriers to Trade (TBT), which is potentially more problematic (Mitchell and Tran 2010).

The choice of implementation scheme for the EU RED standard creates some additional concerns in terms of WTO consistency. Bilateral or multilateral agreements provide an option for addressing trade conflicts directly; as such, they are less likely to pose a problem. However, the legality of voluntary schemes used under the EU RED could be challenged, as such schemes are considered private and are not covered by international agreements made through the WTO. Nearly all of the voluntary schemes are associated with organisations based in developed countries, mainly in Europe. At the same time, biofuels viewed as non-compliant with these schemes are much more likely to come from (tropical) developing countries. Since this affects the sale of those non-compliant biofuels, there is an inherent inconsistency with both the GATT and the TBT agreements (Johnson 2011).

\subsubsection{Creating compliance hurdles}

Certification systems, as proposed in the frameworks analysed in this report, set a minimum level that must be reached for certification to be awarded. This approach runs the risk of the minimum standard being difficult for a badly run project to achieve - or even impossible to achieve because of inability to meet a requirement such as stating the actual date of deforestation. This problem might arise more often in the forestry sector, in which projects usually run for several years, than in the biofuel sector, in which projects are largely being started afresh. However, if requirements are too stringent, especially in a country with weak or even non-existent national frameworks, companies may opt for non-certified production rather than certified production. In this situation, an ISO approach, which incrementally increases environmental performance, might 
prove more acceptable to the industry than an approach that demands full PCI compliance from the beginning. However, an ISO approach may not be feasible for certain aspects where a more stringent or else minimum threshold may be needed (e.g. prohibiting forest conversion). Thus a tiered approach, where some standards should be applied uniformly, while others can be improved over time, may be an option.

As already mentioned, the cost of certification is a concern and is likely to be disproportionally higher for developing countries than for developed countries. This could be seen as giving developed countries an unfair advantage in biofuel production. Moreover, there is evidence from forestry certification (FSC) that the cost may be higher for small-scale producers than for large-scale producers (Pattberg 2006, Zarrilli and Burnett 2008). This could discourage small-scale feedstock production models, despite their potential to better support the development ambitions of developing countries. In addition, developing countries tend not to have the infrastructure for certification. This could create a major barrier to small-scale farming models in developing countries and hence undermine the development potential of biofuels in developing countries.

\subsubsection{Leakage}

Probably the biggest shortcoming of market-based instruments involving certification via PCI is that they target individual producers, rather than the entire sector (in this sense, the EU-RED bilateral agreement option is advantageous). Hence, this approach fails to take into account macro-level impacts, including what is often termed 'leakage'. In the case of biofuels, there are two key areas of concern regarding potential leakage: indirect LUC and impacts on food security (Vis et al. 2008, Zarrilli and Burnett 2008). None of the frameworks investigated here effectively tackles indirect LUC. In addition, several indirect socioeconomic effects, such as increased land prices, rural or urban poverty, displacements and migration (both towards and away from biofuel developments) and diminished access to resources, are difficult to quantify and link causally to a specific development. The issue of indirect deforestation is of particular concern as it may offset positive GHG benefits from biofuels and hence nullify one of the key reasons for European support of biofuel production. Accounting for indirect deforestation is difficult - or even impossible - to monitor through projectlevel certification (Bird et al. 2010). 



\section{Conclusions}

A s Raghu et al. (2011) put it, 'the emerging biofuel economy is likely to result in the single largest reconfiguration of the agricultural landscape since the advent of industrial agriculture. In theory, it is the aim of biofuel sustainability frameworks to ensure that such reconfiguration takes place with due consideration of environmental impacts and conservation of forests and other natural ecosystems that provide critical services to human populations. That said, the following points emerge from this review:

- Although the frameworks share broad overall sustainability goals, principles and criteria, they differ greatly in terms of their coverage and how they apply specific indicators (and develop verifiable indicators) for assessment of the environmental impacts of biofuel production and related accounting of greenhouse gas emissions.

- It is not yet clear which of the frameworks analysed here would best ensure minimal impacts from land use change (both direct and indirect), including allocation of 'degraded' land for feedstock cultivation. In particular, none of the standards specifically promotes land use planning or cultivation on abandoned or degraded land to mitigate leakage. Guidance on how to operationalise 'land degradation' for the purposes of biofuel cultivation is also lacking. Attempts at operationalising 'degradation' should include at least a carbon component (while not disregarding biodiversity and social concerns).
- Issues related to access to and management of fresh water resources are underdeveloped in the reviewed standards as they relate to competition with food crops for water. As in the case of greenhouse gas emissions, there appears to be no consistency in accounting for water footprint estimates. It may be necessary to consider groundwater, irrigation, transpiration and water cycles, depending on the type of crop and its water use efficiencies. The use of catchmentlevel integrated water resource management is one mechanism to ensure that equitable water allocations safeguard strategic water uses.

- There are unresolved issues regarding the best options for implementing sustainability concerns: through gradual, improvement-based certification systems (e.g. ISO) vs. criteria and indicator approaches; harmonised global sustainability frameworks vs. feedstock specific frameworks; or mandatory vs. market-based or voluntary schemes. These conflicts arise partly because of the lack of documented practical experience, as existing biofuel sustainability frameworks have been implemented only recently and further efforts will be required to systematically document progress during implementation. Designing tiered approaches to compliance may provide room for middle ground, so that some aspects can be tackled through adherence to strict standards (related for example to habitat conversion) while compliance of other aspects can be systematically improved over time. 
- No clear consensus exists on which criteria and indicators are so critical as to be included in all circumstances or which sustainability framework should become the global or international standard. The Global Bioenergy Partnership's list of global indicators is the most robust and inclusive of the main dimensions of biofuel production, processing and transport, generated through stakeholder consensus. From the standpoint of operationalisation and specific guidance, however, the Roundtable on Sustainable Biofuels framework has broader applicability and flexibility.

- Any global standard may be less effective and/or less desirable compared to regional standards, which can be better tuned to the level of economic development and the particular climatic and physical circumstances, while at the same time offering greater economic flexibility and administrative savings than a collection of national schemes.

- Sustainability frameworks derived from roundtables such as the RSPO may need to develop real monitoring and enforcing capabilities or else partner with an organisation that has such capacities (see Laurance et al. 2010). In this respect, the FSC can serve as a model for those roundtables with clear stakeholder imbalances, such as the RSPO and other pro-industry groups.

In the absence of sufficient hard data with which to gauge the effectiveness of existing sustainability frameworks in mitigating the impacts of direct and indirect land use change and in promoting environmental conservation, the following recommendations for improvement are offered:

- As sustainability frameworks are only a means to an end, they must be supported by practical guidance, effective interpretation of standards, principles and criteria, and provision of appropriate tools, approaches and capacity building activities. Biofuel sustainability frameworks, whether mandatory or voluntary, may not be enough to mitigate the impacts of direct and indirect land use change, and so should be complemented by other policy instruments particularly at the national level.

- Avoiding indirect land use change will be almost impossible to control solely through projectlevel certification of good practice. Additionally, enhancing productivity in the agricultural sector could help to reduce indirect land use change, especially in regions where production levels are currently low by international standards. The application of integrated approaches to land use planning that consider biodiversity aspects as well as agricultural practices where biodiversity issues are inserted may also be needed. National policies should also be developed to encourage effective land use planning and application of agricultural best practice. The eco-agriculture literature explores many practices that can be adapted to any biofuel production operation, including agro-ecological zoning.

- The temporal nature of emissions following land management changes requires that for shortterm reductions in greenhouse gas emissions, a greater emphasis must be placed on biomass that would either be quickly regrown or else quickly decompose. The former drives bioenergy development to crop-derived biomass and the resulting potential for indirect land use change. The second type of biomass is less prone to indirect land use change but - depending on the intensity of extraction - may negatively affect nutrient cycles and long-term sustainability. These points are often not addressed in sustainability frameworks and may need further development. 


\section{References}

Auld, G., Gulbrandsen, L. and McDermott, C. 2008 Certification schemes and the impacts on forests and forestry. Annual Review of Environment and Resources 33: 187-211.

Bird, N., Pena, N., Schwaiger, H. and Zanchi, G. 2010 Review of existing methods for carbon accounting. Occasional paper 54. CIFOR, Bogor, Indonesia. http://www. cifor.org/publications/pdf_files/WPapers/ WP54CIFOR.pdf.

Buchholz, T., Luzardis, V.A. and Volk, T.A. 2009 Sustainability criteria for bioenergy systems: results from an expert survey. Journal of Cleaner Production 17: S86-S98.

Cashore, B., Galloway, G., Cubbage, F., Humhreys, D., Katila, P., Levin, K., Maryudi, A., McDermott, C., McGinley, K., Kengen, S. et al. 2010 Ability of institutions to address new challenges. In: Mery, G., Katila, P., Galloway, G., Alfaro, R.I., Kanninen, M., Lobovikov, M. and Varjo, J. (eds.) Forests and society: responding to global drivers of change, 441486. IUFRO World Series 25, Vienna, Austria.

Cashore, B., van Kooten, G.C., Vetinsky, I., Auld, G. and Affolderbach, J. 2005 Private or selfregulation? A comparative study of forest certification choices in Canada, the United States and Germany. Forest Policy and Economics 7: 35-69.

Echols, M.A. 2009 Biofuels certification and the law of the World Trade Organization. ICTSD Programme on Agricultural Trade and Sustainable Development, Issue Paper 19. International Centre for Trade and Sustainable Development, Geneva, Switzerland.

El Bassam, N. 2010 Handbook of bioenergy crops: a complete reference to species, development and applications. Earthscan, London, UK.

European Commission (EC) 2008 Commission staff working document - annex to the impact assessment, package of implementation measures for the EU's objectives on climate change and renewable energy for 2020. 27.2.2008, SEC (2008) 85. European Commission, Brussels, Belgium.

FAO 2009 Towards defining forest degradation: Comparative analysis of existing definitions. Forest Resources Assessment Working Paper 154. Food and Agriculture Organization, Rome, Italy.

Fritsche, U.R., Hennenberg, K.J., Hünecke, K., Herrera, R. and Wiegmann, K. 2011 Sustainable bioenergy: key criteria and indicators. Öko-Institut, Darmstadt, Germany.

Gao Y., Skutsch M., Masera O. and Pacheco, P. 2010 A global analysis of tropical deforestation due to bioenergy development. Report for Activity 1.1 of the project 'Bioenergy, sustainability and trade-offs: Can we avoid deforestation while promoting bioenergy?' CIFOR, Bogor, Indonesia.

Gibbs, H.K., Ruesch, A.S., Achard, F., Clayton, M.K., Holmgren, P., Ramankutty, N. and Foley, J.A. 2010 Tropical forests were the primary sources of new agricultural land in the 1980s and 1990s. Proceedings of the National Academy of Sciences USA 107: 16732-16737.

Global Bioenergy Partnership 2011 GBEP Sustainability indicators for bioenergy. http:// www.globalbioenergy.org/fileadmin/user_ upload/gbep/docs/2011_events/11th_TF_ Sustainability_Stockholm_15-17_March_2011/ indicators/names_and_descriptions.pdf (7 September 2011).

Groom, M.J., Gray, E.M. and Townsend, P.A. 2008 Biofuels and biodiversity: principles for creating better policies for biofuel production. Conservation Biology 22: 602-609.

Guariguata, M.R., Nasi, R. and Kanninen, M. 2009 Forest degradation: it is not a matter of new definitions. Conservation Letters 2: 286-287. 
Hennenberg, K.J., Dragisic, C., Haye, S., Hewson, J., Semroc, B., Savy, C., Wiegmann, K., Fehrenbach, H. and Fritsche, U.R. 2010 The power of bioenergy-related standards to protect biodiversity. Conservation Biology 24: 412-423.

Hetemäki, L., Mery, G., Holopainen, M., Hyppä, J., Vaario, L.M. and Yrjälä 2010 Implications of technological development to forestry. In: Mery, G., Katila, P., Galloway, G., Alfaro, R.I., Kanninen, M., Lobovikov, M. and Varjo, J. (eds) Forests and society: responding to global drivers of change, 157-179. IUFRO World Series 25, Vienna, Austria.

Johnson, F.X. 2011 Regional-global linkages in the energy-climate-development policy nexus: the case of biofuels in the EU Renewable Energy Directive. Renewable Energy Law and Policy Review 2: (in press).

Kaditi, E.A. 2009 Bio-energy policies in a global context. Journal of Cleaner Production 17: S4-S8

Laurance, W.F., Koh, L.P., Butler, R., Sodhi, N.S., Bradshaw, C.J.A., Neidel, J.D., Consunji, H. and Mateo Vega, J. 2010 Improving the performance of the Roundtable on Sustainable Palm Oil for nature conservation. Conservation Biology 24: 377-381.

Macedo, I. 2005 Sugar cane's energy: twelve studies on sugar cane agribusiness and its sustainability. Brazilian Sugarcane Industry Association (UNICA), Sao Paolo, Brazil.

Marx, A. and Cuypers, D. 2010 Forest certification as a global environmental governance tool: What is the macro-effectiveness of the Forest Stewardship Council? Regulation and Governance 4: 408-434.

Mitchell, A. and Tran, C. 2010 The consistency of the European Union Renewable Energy Directive with World Trade Organization agreements: the case of biofuels. Renewable Energy Law and Policy Review 1: 33-44.

Mol, A.P.J. 2007 Boundless biofuels? Between environmental sustainability and vulnerability. Sociologia Ruralis 47: 297-315.

Nabuurs, G.J., Masera, O., Andrasko, K., BenitezPonce, P., Boer, R., Dutschke, M., Elsiddig, E., Ford-Robertson, J., Frumhoff, P., Karjalainen, T. et al. 2007 Forestry In: Metz, B., Davidson, O.R., Bosch, P.R., Dave, R. and Meyer, L.A. (eds) Climate change 2007: mitigation. Contribution of Working Group III to the fourth assessment report of the Intergovernmental Panel on Climate Change, 542-584. Cambridge University Press, Cambridge, UK.
Pattberg, P. 2006 Lessons from global forest politics. Third World Quarterly 27: 579-593.

Raghu, S., Spencer, J.L., Davis, A.S. and Wiedenmann, R.N. 2011 Ecological considerations in the sustainable development of terrestrial biofuel crops. Current Opinion in Environmental Sustainability 3: 15-23.

Sapp, M. 2010 Creating value in African biofuels. Biofuels, Bioproducts and Biorefining 4: 366-368.

Scarlat, N. and Dallemand, J.F. 2011 Recent developments of biofuels/bioenergy sustainability certification: a global overview. Energy Policy 39: 1630-1646.

Scheppers, D.H. 2010 Challenges to legitimacy at the Forest Stewardship Council. Journal of Business Ethics 92: 279-290.

Scherr, S.J. and McNeely, J.A. 2007 Farming with nature: the science and practice of ecoagriculture. Island Press, Washington, DC.

Schoneveld, G.C. 2010 Potential land use competition from first-generation biofuel expansion izzn developing countries. Occasional paper no. 58. CIFOR, Bogor, Indonesia.

Schubert, R. and Blasch, J. 2010 Sustainability standards for bioenergy - a means to reduce climate change risks? Energy Policy 38: 2797-2805.

Smeets, E., Junginger, M., Faaij, A., Walter, A. and Dolzan, P. 2006 Sustainability of Brazilian bioethanol. Report NWS-E-2006-110. Universiteit Utrecht, Copernicus Institute and UNICAMP, Netherlands.

Solomon, B.D. 2010 Biofuels and sustainability. Annals of the New York Academy of Sciences 1185: 119-134.

Van Dam, J., Junginger, M., Faaij, A., Jürgens, I., Best, G. and Fritsche, U. 2008 Overview of recent developments in sustainable biomass certification. Biomass and Bioenergy 32: 749-780.

Vis, M.W., Vos, J. and van den Berg, D. 2008 Sustainability criteria and certification systems for biomass production. A report prepared for DG TREN - European Commission. Project 1386. Biomass Technology Group, Enschede, Netherlands. http://ec.europa.eu/energy/ renewables/bioenergy/doc/sustainability_ criteria_and_certification_systems.pdf (7 September 2011).

Zarrilli, S. and Burnett, J. 2008 Making certification work for sustainable development: the case for biofuel. United Nations Conference on Trade and Development, Geneva, Switzerland. 

CIFOR Occasional Papers contain research results that are significant to tropical forestry.

The content is peer reviewed internally and externally.

With the rapid growth of biofuel production and consumption and the proliferation of policy decisions supporting this expansion, concerns about the biofuel sector's environmental and social impacts are increasing. Consequently, a range of actors - among them governments, multilateral institutions, nongovernmental organisations and multistakeholder industry groups - have created sustainability frameworks, some mandatory, others voluntary. This report examines how the most developed sustainability frameworks for feedstock production (including biofuels) address key environmental issues. It identifies critical gaps in these frameworks and proposes areas for improvement.

The main finding is that the frameworks share broad sustainability principles yet they differ greatly in terms of their comprehensiveness and how they apply specific indicators for environmental issues, particularly with respect to land use change (both direct and indirect), allocation of degraded land for feedstock cultivation, and related accounting of greenhouse gas emissions.

In the absence of sufficient hard data with which to gauge the effectiveness of existing sustainability frameworks, the report notes that the standards of these frameworks are not sufficient to mitigate the effects of direct and indirect land use change and promote environmental conservation. A key recommendation is that such standards should be complemented by other policy instruments. Furthermore, as sustainability frameworks are only a means to an end, they must be supported by practical guidance, effective interpretation of standards, principles and criteria, and development of verifiable indicators, along with the provision of appropriate tools, approaches and capacity building activities.

www.cifor.org

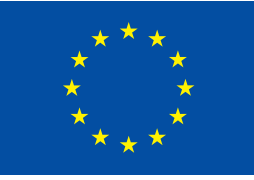

